\title{
EVIDÊNCIA CIENTÍFICA DOS MÉTODOS DE APLICAÇÃO DE GÉIS FLUORETADOS: UMA REVISÃO INTEGRATIVA
}

\author{
$\underline{\text { Silvia Letícia Sena Ferreira }}{ }^{1}$; Hervânia Santana da Costa ${ }^{2}$; Carlos Sampaio de Santana \\ Neto 3 e Ana Rita Guimarães Duarte ${ }^{4}$ \\ 1 Bolsista PIBIC/FAPESB, Graduando em Odontologia, Universidade Estadual de Feira de Santana, e-mail: \\ silvialsena@gmail.com \\ 2 Orientador, Departamento de Saúde, Universidade Estadual de Feira de Santana, e-mail: hervacosta@gmail.com \\ 3 Participante do projeto, Departamento de Saúde, Universidade Estadual de Feira de Santana, e-mail: cs.neeto@gmail.com \\ 4 Participante do projeto, Departamento de Saúde, Universidade Estadual de Feira de Santana, e-mail: $\underline{\operatorname{ardg} 1999 @ \text { gmail.com }}$
}

PALAVRAS-CHAVE: Fluoretos Tópicos; Cárie Dentária; Saúde Bucal.

\section{INTRODUÇÃO}

A cárie dentária acomete indivíduos de todas as faixas etárias e níveis socioeconômicos, sendo a enfermidade de maior prevalência na cavidade bucal, é considerada um dos principais agravos em Saúde Pública no Brasil. É uma doença crônica que acarreta a desmineralização da superfície dental por meio da produção de ácidos pelas bactérias (LEAL et al., 2015).

Com a finalidade de diminuir a incidência desta doença e controlar o agravamento das lesões de cárie, realizando-se a paralisação das lesões iniciais, tem-se a utilização do flúor (SALAZAR, 2008).

A fluoretação tópica na forma de géis, dentifrícios, soluções e vernizes tem sido empregada por várias décadas (LIRA et al., 2013). Com toda essa variedade de métodos e com diferentes concentrações, a utilização de mais de um dos mesmos torna-se preocupante, principalmente quando a aplicação é feita em crianças de zero a seis anos de idade, uma vez que é nesse período que há a formação dos dentes permanentes e há risco de ocorrência de fluorose dentária, que ocorre a partir da ingestão constante de pequenas quantidades de flúor durante a formação do germe dentário (ALMEIDA et al., 2007).

Os géis fluoretados são de uso profissional em ambiente clínico, podendo ser aplicados de várias maneiras: com o auxílio de moldeiras, escovas dentais, cotonetes, dentre outras. As moldeiras se apresentam como um bom método para aplicação tópica de flúor por ser de fácil uso, porém, não se consegue o controle da deglutição pelas crianças. O emprego de cotonetes apresenta desvantagens: a falta de adesão do material ao instrumento, podendo ser facilmente deglutido; o produto não consegue atingir as faces interproximais dos dentes; mais tempo para aplicação, pois deve ser feita em uma hemi-arcada de cada vez. Quando aplicado com o auxílio da escova de dente, o uso dos géis fluoretados deve ser supervisionado por um profissional, pois, há grande chance de deglutição pela criança. Portanto, o Cirurgiãodentista deve avaliar as características individuais de cada paciente para escolher dentre os métodos de aplicações tópicas (DIAS, 2009).

Com o advento da Odontologia Baseada em Evidências, a escolha de uma prática clínica em detrimento de outra, faz-se a partir de estudos que tenham melhor nível de evidência. Desta forma, diante das controvérsias no que diz respeito ao método de aplicação tópica de flúor gel, faz-se necessário a investigação do nível de evidência dos estudos publicados nesta área. $\mathrm{O}$ uso de uma metodologia tipo revisão integrativa fornecerá o conhecimento mais abrangente de um fenômeno específico a partir do agrupamento de resultados de pesquisas primárias (COOPER, 1982).

\section{MATERIAIS E MÉTODOS}

A revisão integrativa foi realizada por meio de levantamento de dados de pesquisas primárias, agrupando os estudos ordenada e sistematicamente. Os critérios de inclusão foram: estudos encontrados sobre o tema em tela divulgados, nos idiomas português, inglês e 
espanhol, sem delimitação de período. Os descritores utilizados foram "Acidulated phosphate fluoride", "Topical, fluorides", "Dental Caries" e "Oral Health", nas bases de dados Lilacs, PubMed e IBICT. Artigos encontrados nas referências de outros artigos que obedeciam aos critérios de inclusão também foram selecionados. Foram excluídos os trabalhos não disponíveis na íntegra e que não atenderem aos critérios de inclusão. A partir da pesquisa, foram selecionados sete artigos, os quais foram fichados e a categorização foi feita de acordo com o critério de Nível de Evidência Científica por Tipo de Estudo - "Oxford Centre for Evidence-based Medicine, 2001" (Figura 1).

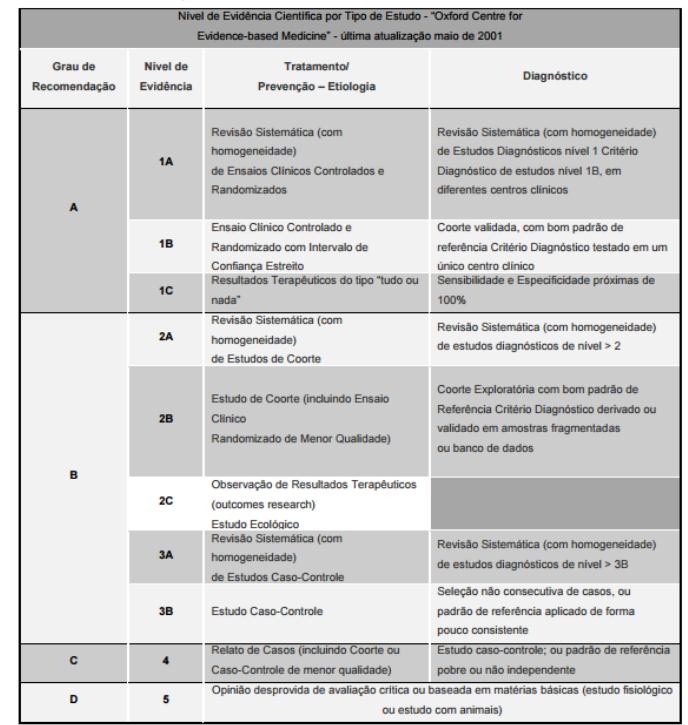

Figura 1 - Tabela retratando o Nível de Evidência por Tipo de Estudo "Oxford Centre for Evidence-based Medicine, 2001" Fonte: AMB-CFM, 2002

\section{RESULTADOS E DISCUSSÃO}

Com base na metodologia descrita, foram encontrados cinco artigos nas bases de dados. Dentre esses artigos, três foram aceitos através dos critérios de inclusão e exclusão, extraídos do PubMed. Quatro artigos foram adicionados manualmente aos aceitos através da busca nas referências dos artigos encontrados, pois não foram encontrados através dos descritores selecionados. Com isto, somou-se sete artigos aceitos para esta revisão integrativa (Tabela 1).

Tabela 1 - Estudos classificados segundo o Nível de evidência Científica por Tipo de Estudo - "Oxford Centre for Evidence-based Medicine, 2001", Feira de Santana, Bahia, 2017 (N = 7).

\begin{tabular}{|c|c|c|c|c|c|}
\hline Autor & Ano & $\begin{array}{l}\text { Desenho de } \\
\text { estudo }\end{array}$ & $\begin{array}{c}\text { Nível de } \\
\text { Evidência }\end{array}$ & Objetivo & Conclusões \\
\hline $\begin{array}{l}\text { RIBEIRO, C., } \\
\text { et al. }\end{array}$ & 2012 & $\begin{array}{l}\text { Ensaio Clínico } \\
\text { Randomizado }\end{array}$ & $1 \mathrm{~B}$ & $\begin{array}{l}\text { Comparar a retenção } \\
\text { salivar após aplicação de } \\
\text { gel usando uma escova } \\
\text { de dentes ou com } \\
\text { moldeiras. }\end{array}$ & $\begin{array}{l}\text { Não há diferença na } \\
\text { retenção de flúor entre os } \\
\text { grupos. }\end{array}$ \\
\hline $\begin{array}{l}\text { WEYANT, } \\
\text { R., et al. }\end{array}$ & 2014 & $\begin{array}{c}\text { Revisão } \\
\text { Sistemática }\end{array}$ & $1 \mathrm{~A}$ & $\begin{array}{l}\text { Auxiliar os profissionais } \\
\text { na tomada de decisões } \\
\text { sobre o uso de agentes } \\
\text { tópicos preventivos de } \\
\text { cárie. }\end{array}$ & $\begin{array}{l}\text { Os fluoretos tópicos } \\
\text { fornecem benefícios } \\
\text { adicionais. A profilaxia } \\
\text { antes do flúor não } \\
\text { melhorou a eficácia. }\end{array}$ \\
\hline $\begin{array}{l}\text { TRUIN, G-J; } \\
\text { VAN'T HOF, } \\
\text { M. }\end{array}$ & 2007 & $\begin{array}{c}\text { Ensaio Clínico } \\
\text { Randomizado }\end{array}$ & $1 \mathrm{~B}$ & $\begin{array}{l}\text { Estudar a eficácia } \\
\text { cariostática da aplicação } \\
\text { de gel de fluoreto } \\
\text { semestral em lesões } \\
\text { cariosas incipientes em } \\
\text { crianças com baixo } \\
\text { índice de cárie. }\end{array}$ & $\begin{array}{l}\text { O gel de fluoreto } \\
\text { aplicado } \\
\text { profissionalmente não } \\
\text { mostrou } \\
\text { estatisticamente } \\
\text { significativo de inibição } \\
\begin{array}{l}\text { de cárie. }\end{array}\end{array}$ \\
\hline
\end{tabular}


Continuação da Tabela 1

\begin{tabular}{|c|c|c|c|c|c|}
\hline Autor & Ano & $\begin{array}{l}\text { Desenho de } \\
\text { estudo }\end{array}$ & $\begin{array}{c}\text { Nível de } \\
\text { Evidência }\end{array}$ & Objetivo & Conclusões \\
\hline $\begin{array}{l}\text { LeCOMPTE, } \\
\text { E.J.; } \\
\text { RUBENSTEI } \\
\text { N, L.K. }\end{array}$ & 1984 & $\begin{array}{l}\text { Ensaio Clínico } \\
\text { Randomizado }\end{array}$ & 1B & 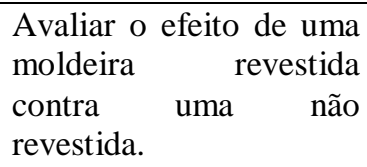 & $\begin{array}{l}\text { Recomenda-se o uso de } \\
\text { uma moldeira revestida } \\
\text { de espuma e dispositivos } \\
\text { de sucção. }\end{array}$ \\
\hline $\begin{array}{l}\text { JOOST } \\
\text { LARSEN, M., } \\
\text { et al. }\end{array}$ & 1985 & $\begin{array}{l}\text { Ensaio Clínico } \\
\text { Randomizado }\end{array}$ & 1B & $\begin{array}{l}\text { Investigar a prevalência } \\
\text { de fluorose dentária em } \\
\text { crianças que receberam } \\
\text { tratamentos de rotina } \\
\text { com gel de fluoreto duas } \\
\text { vezes ou mais a cada } \\
\text { ano. }\end{array}$ & $\begin{array}{l}\text { Os tratamentos de gel de } \\
\text { fluoreto semianuais } \\
\text { iniciados com a idade de } \\
6 \text { anos não levam a uma } \\
\text { maior prevalência de } \\
\text { fluorose. }\end{array}$ \\
\hline $\begin{array}{l}\text { MARINHO, } \\
\text { V., et al. }\end{array}$ & 2003 & $\begin{array}{c}\text { Revisão } \\
\text { Sistemática }\end{array}$ & $1 \mathrm{~A}$ & \begin{tabular}{lrr} 
Avaliar a & \multicolumn{2}{c}{ eficácia e } \\
segurança dos géis \\
fluoretados & & na \\
prevenção da cárie \\
dentária em crianças e \\
examinar os principais \\
fatores que \\
influenciar podem \\
eficácia. a
\end{tabular} & $\begin{array}{l}\text { A ATF está associada à } \\
\text { paralisação de lesões de } \\
\text { cáries. A avaliação das } \\
\text { possíveis diferenças de } \\
\text { efeito dos métodos de } \\
\text { aplicação do flúor gel } \\
\text { deve basear-se em } \\
\text { ensaios os comparem } \\
\text { diretamente.. }\end{array}$ \\
\hline
\end{tabular}

Diante dos resultados expostos, poucos artigos foram encontrados acerca do tema proposto. Embora o nível de evidência científica dos estudos encontrados tenha sido alto, não pode-se dizer que há embasamento científico para o melhor protocolo para aplicação tópica de flúor gel.

Apenas dois dos sete estudos analisados comparam métodos de aplicação tópica do flúor gel. Após comparar a retenção do flúor na saliva depois da aplicação do gel usando escova de dentes ou moldeiras, Ribeiro e colaboradores (2012) concluíram que não há diferença na retenção do flúor com o uso dos dois métodos, mas eles indicam o uso da escova de dentes pelo fato de o profissional conseguir controlar a deglutição pela criança.

O segundo estudo que comparou diferentes métodos foi o de LeCOMPTE e RUBENSTEIN (1984). Quando compararam dois tipos de moldeiras, uma revestida com espuma e outra sem revestimento, concluíram que é melhor que se use a moldeira revestida com o auxílio de dispositivos de sucção.

Poucos são os estudos que comparam diretamente os diferentes métodos de aplicação de flúor gel, dificultando a criação de um protocolo que identifique um melhor método em detrimento do outro. Esse resultado também foi encontrado por Marinho e colaboradores (2013) em sua revisão sistemática, onde é comprovado que a comparação das possíveis diferenças de efeito associadas aos métodos de aplicação tópica de flúor só podem ser avaliadas quando analisadas de forma comparativa.

\section{CONSIDERAÇÕES FINAIS}

A escassez de estudos sugere que não existe uma prática de aplicação de géis fluoretados com base na evidência científica. $\mathrm{Na}$ atualidade, recomenda-se a utilização de técnicas na Odontologia com base em estudos científicos. Com isto, necessita-se de mais pesquisas sob desenhos de estudo do tipo Ensaio Clínico Randomizado que possam indicar uma prática clínica de aplicação de géis fluoretados à luz da evidência científica. 


\section{REFERÊNCIAS}

ALMEIDA, G. J. F., et al. Indicações de odontopediatras quanto ao uso de flúor tópico por crianças entre zero e seis anos de idade: dados para a elaboração de um protocolo de ações. Salusvita, Bauru, v. 27, n. 3, p. 373-392, 2007.

AMB-CFM. Associação Médica Brasileira e Conselho Federal de Medicina. Projeto Diretrizes. 9p, Brasília, 2002. Disponível em:

<http://www.portalmedico.org.br/diretrizes/100_diretrizes/Texto_Introdutorio.pdf $>$. Acesso em: 30/03/2016.

COOPER, H. M. Scientific guidelines for conducting integrative research reviews. Review of Educational Research, v. 52, n. 2, p. 291-302. 1982.

DIAS, H. G. V. Técnicas clínicas de aplicação tópica de flúor. 2009. 40f. Trabalho de Conclusão de Curso (Graduação) - Faculdade de Odontologia de Piracicaba, Universidade Estadual de Campinas, Piracicaba, 2009.

JOOST LARSEN, M., et al. Prevalence of Dental Fluorosis after Fluoride-gel Treatments in a Low-fluoride Area. J Dent Res, Florida. v.64, n.8. p.1076-1079, 1985.

LEAL, S.D.; CARVALHO, F. S.; CARVALHO C. A. P. Conhecimento de alunos do Curso de Odontologia sobre o uso racional do flúor. Rev. Odontol. UNESP, São Paulo, Jan.-Fev. v. 44, n.1, p. 51-58, 2015.

LeCOMPTE, E.J.; RUBENSTEIN, L.K. Oral Fluoride Retention with Thixotropic and APF Gels and Foam-lined and Unlined Trays. J Dent Res, Florida. v.63, n.1. p.69-70, 1984.

LIRA, A. M. et al. Efeito da aplicação tópica de um verniz de TiF4 quimicamente estável na desmineralização do esmalte dentário bovino: estudo in vitro. Rev. Odontol. UNESP, São Paulo, Set-Out, v. 42, n. 5, p. 372-377, 2013.

MARINHO, V.C.C., et al. Systematic Review of Controlled Trials on the Effectiveness of Fluoride Gels for the Prevention of Dental Caries in Children. Journal of Dental Education, Londres. v.67,n.4. p. 448-458. 2003.

PINTO, I.L. Prevenção da cárie dental com aplicações tópicas semestrais de flúor-fosfato acidulado. Rev. Saúde Pública, Brasília. v. 27. p. 277-90, 1993.

RIBEIRO, C.C.C., et al. Salivary retention after application of fluoride gel using toothbrush or tray: a crossover trial. Braz Oral Res., São Paulo, Nov-Dez; v. 26, n.6, p.493-7, 2012.

SALAZAR, Mariana. Efetividade da aplicação semestral de verniz fluoretado no controle da cárie dentária em pré-escolares: resultados após 12 meses de acompanhamento. 2008. 62f. Dissertação (Mestrado em Odontologia) - Faculdade de Odontologia, Universidade do Estado do Rio de Janeiro, Rio de Janeiro, 2008.

TRUIN, G-J; VAN'T HOF, M. The effect of fluoride gel on incipient carious lesions in a low-caries child population. Community Dent Oral Epidemiol. Holanda, v.35 250-254. 2007.

WEYANT, R.J., et al. Topical Fluoride for Caries Prevention; Full report of the updated clinical recommendations and supporting systematic review. American Dental Association. Chicago, 2013. 